\title{
Quantum-Dot and Polychalcone Mixed Nanocomposites for Polymer Light-Emitting Diodes
}

\author{
Vanaraj Ramkumar and Sanghyun Ju \\ Department of Physics, Kyonggi University, Suwon, Gyeonggi-Do 16227, Republic of Korea \\ Correspondence should be addressed to Sanghyun Ju; shju@kgu.ac.kr
}

Received 5 July 2017; Accepted 26 September 2017; Published 23 October 2017

Academic Editor: Youngjae Park

Copyright ( 2017 Vanaraj Ramkumar and Sanghyun Ju. This is an open access article distributed under the Creative Commons Attribution License, which permits unrestricted use, distribution, and reproduction in any medium, provided the original work is properly cited.

\begin{abstract}
The present work is aimed at improving the efficiency of light-emitting diodes (LEDs) through the amalgamation of polymeric materials and quantum dots (QDs) in nanocomposites. Herein, we report on the polytriphenylamine-based chalcone (PTpC) or polycarbazole-based chalcone- (PCzC-) QDs mixture nanocomposites as emissive layers for polymer LEDs (PLEDs). QDs were evenly dispersed in the polymer matrix and the synthesized PTpC-QDs and PCzC-QDs nanocomposites were able to form smooth thin films. The luminance characteristics of PTpC-QDs and PCzC-QDs nanocomposites were better than those of the pristine $\mathrm{QD}, \mathrm{PTpC}$, and $\mathrm{PCzC}$ materials, owing to the high charge-carrier transport ability of polymer-QDs nanocomposites. These results indicate that the proposed polymer-QDs nanocomposites could be potential candidates for application in PLEDs.
\end{abstract}

\section{Introduction}

Recently, significant efforts have been placed in developing high-performance polymeric materials in optoelectronic applications, including polymer light-emitting diodes (PLEDs) [1-3]. The PLEDs with multilayer structures (hole injection layer (HIL)/hole transfer layer (HTL)/emission layer (EML)/electron transfer layer (ETL)/electron injection layer (EIL)) should theoretically show better electrooptical characteristics compared to PLEDs with unilayer (EML only) and bilayer structures (HIL/EML) [4-6]. However, there are performance degradation issues during the formation of multilayers $[6,7]$. In order to solve this issue, conjugated polymerbased LEDs have received particular attention because the conjugated polymer could provide a high carrier transport ability, which could play a multiple role as HTL, ETL, and EIL, in the EML [8-10]. As a result, conjugated polymer-based LEDs could provide high-performance properties in terms of high luminance, high efficiency, and low voltage operation, while allowing for inexpensive and easier fabrication process techniques [4-6]. Among conjugated polymers, several studies have been conducted on polymer-nanoparticle mixtures, especially polymer quantum dots (QDs) materials [11-14]. In polymer-nanoparticle composites, the uniform dispersion of nanoparticles offers advantages over those cases where nanoparticle aggregation dominates. In addition, polymers with different architectures, such as homo- and copolymers, hyperbranched polymers, and polymeric nanogels, have been employed to anchor and coat QDs for fabricating photonic polymer-QDs materials $[14,15]$.

QDs materials have been widely used to fabricate display devices because of their unique physical properties, especially their tunable band gap energy derived by tuning the particle size, which generates the quantum confinement effect [7]. However, because of their charge immobility, indissolubility, and photoluminescence instability, QDs usually need to be modulated by a passivation process to increase the luminance efficiency of the device [8]. To achieve this goal, polymers with excellent charge mobility and high stability are widely employed to modify the QDs for display and photonic applications $[9,10]$. The modification of QDs including surface functionalization could improve the photoluminescence quantum yield for organic or inorganic capped nanoparticles $[10,11]$. On the other hand, inorganic nanoparticles, including QDs, generally produce poor film formation because they are based on powders, which results in the disconnection between nanoparticles. Therefore, the nanoparticles should be uniformly dispersed in conductive solution-based 


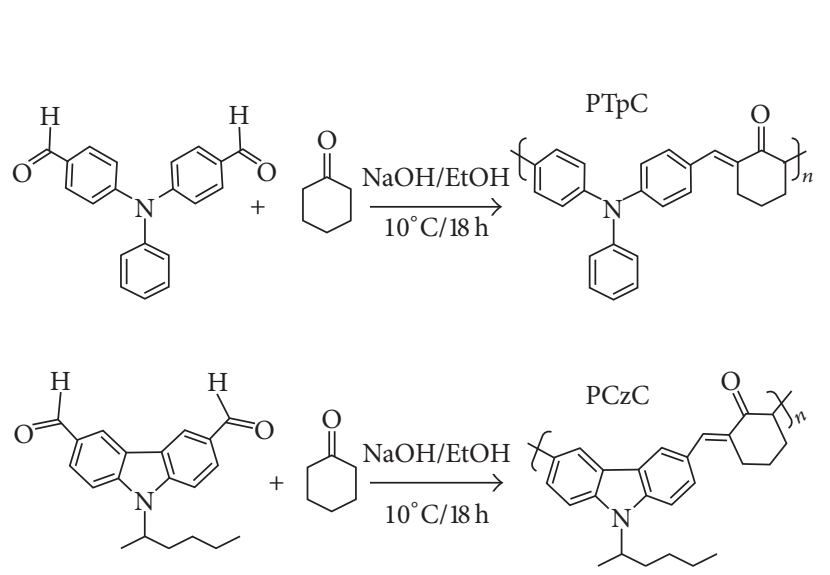

(a)

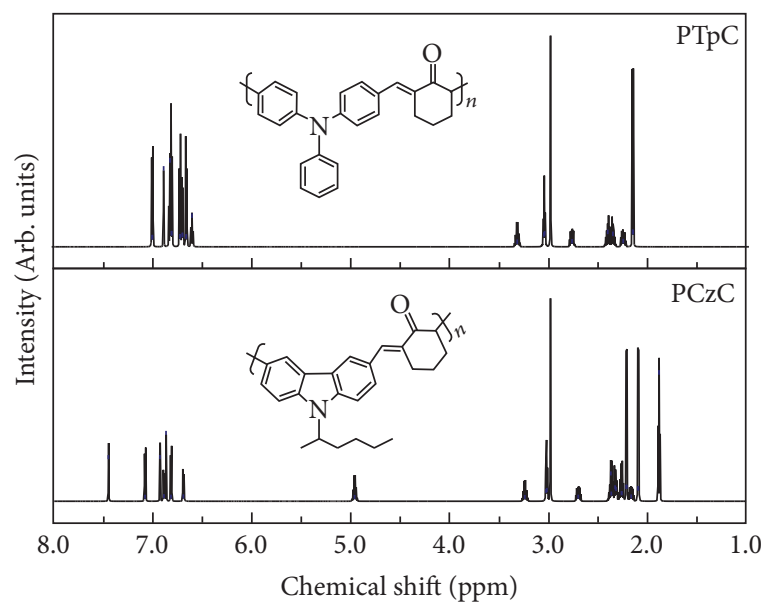

(c)

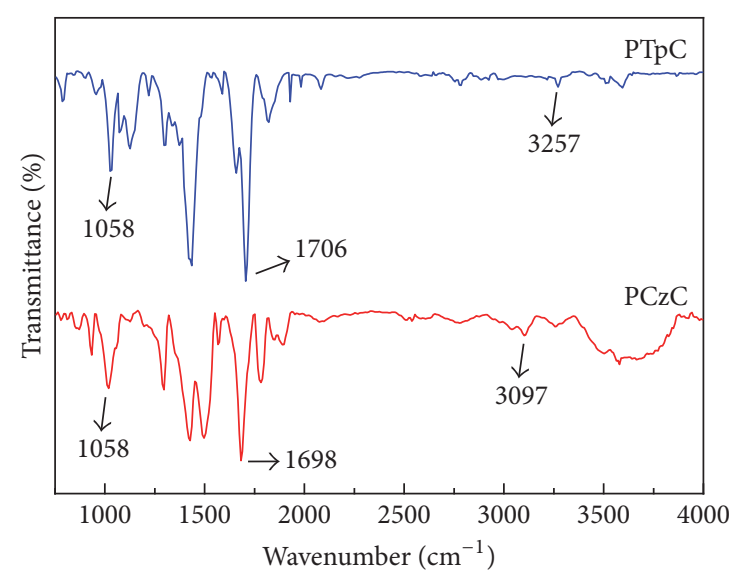

(b)

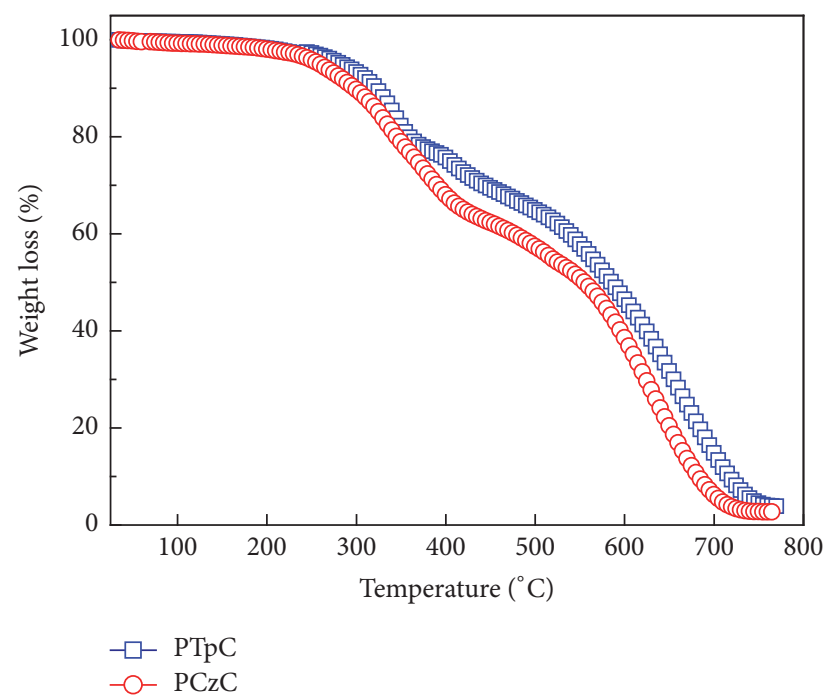

(d)

Figure 1

polymers, which could connect the inorganic nanoparticles by providing high charge-carrier mobility $[11,12]$.

In this study, polymer-QDs (PTpC-QDs and PCzCQDs) nanocomposites were synthesized, and their chemical structures and optical properties were investigated. The two polymers, PTpC and PCzC, were combined with QDs by surface functionalization. The synthesized PTpC-QDs and PCzC-QDs nanocomposites were used to fabricate PLED devices as an EML, and their luminescence characteristics were compared with those of the LEDs with the pristine PTpC, PCzC, and QDs.

\section{Experimental Section}

Synthesis of polymers (PTpC and PCzC) and polymer-QDs nanocomposites (PTpC-QDs and PCzC-QDs): Cyclohexanone, 4,4'-diformyltriphenylamine, 9-(2-ethylhexyl)carbazole-3,6-dicarboxaldehyde, sodium hydroxide, ethanol, and QDs(CdSeS@ZnS for red, CdZnSeS@ZnS for green, and
CdZnS@ZnS for blue) were used to synthesize PTpC, $\mathrm{PCzC}, \mathrm{PTpC}-\mathrm{QDs}$, and PCzC-QDs. The analogous chalcone polymers (PTpC and $\mathrm{PCzC}$ ) were synthesized by using the standard Claisen-Schmidt condensation reaction from the respective aldehydes and ketone [15]. For PTpC, equimolar $(0.009 \mathrm{mmol})$ of aldehyde $\left(4,4^{\prime}\right.$-diformyltriphenylamine) and ketone (cyclohexanone) were dissolved in absolute ethanol $(60 \mathrm{~mL})$ and the mixture was stirred at $10^{\circ} \mathrm{C}$ for $30 \mathrm{~min}$. An aqueous solution of sodium hydroxide $(5 \mathrm{~mL}$, $10 \%)$ was slowly added to the reaction mixture. At the end of the reaction $(6 \mathrm{~h})$, the mixture was poured onto ice-cold water $(500 \mathrm{~mL})$ and set aside for $10 \mathrm{~h}$. The precipitated crude solid was collected by filtration, dried in a hot air oven, and purified by repeated methanol [9]. A similar procedure was adopted to synthesize the polymer $\mathrm{PCzC}$, from the respective aldehyde (9-(2-ethylhexyl)carbazole-3,6-dicarboxaldehyde) and ketone (cyclohexanone). The molecular weight of the polymers was obtained by gel permeation chromatography, and the molecular weights of PTpC and $\mathrm{PCzC}$ were 9750 


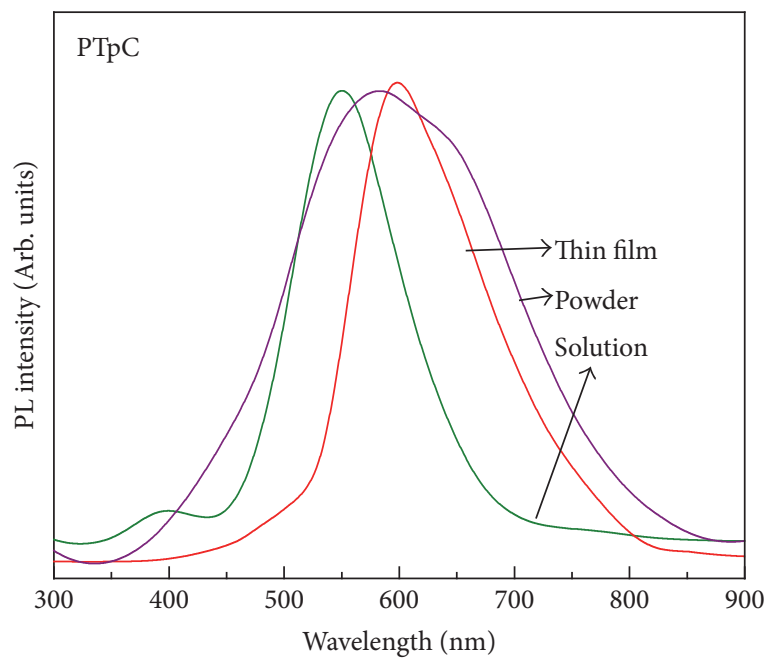

(a)

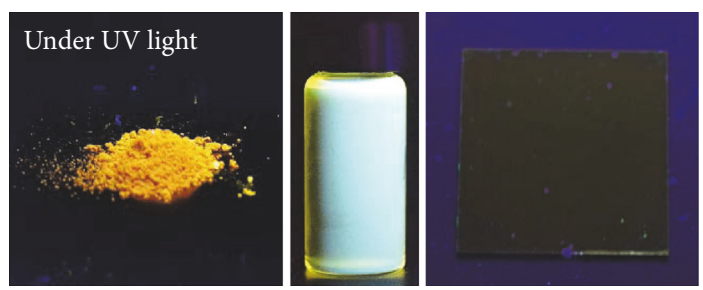

(c)

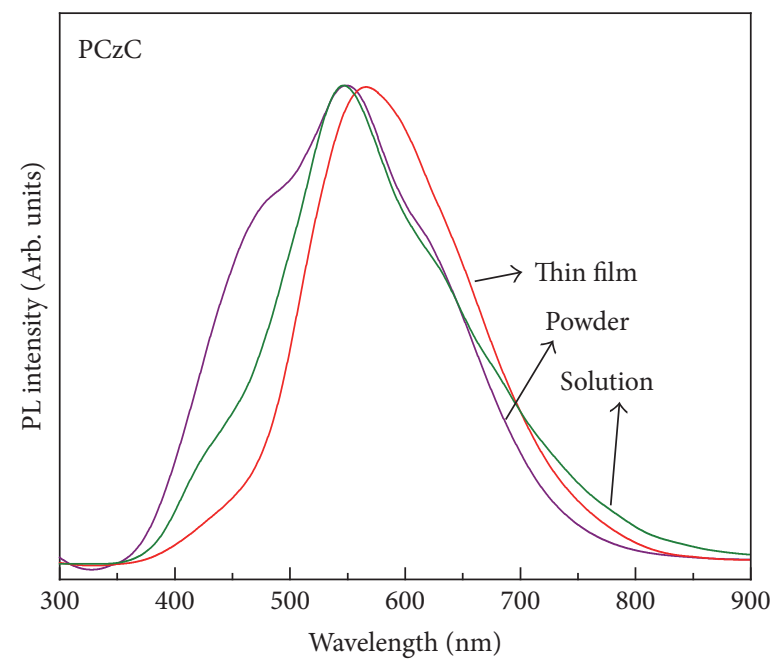

(b)
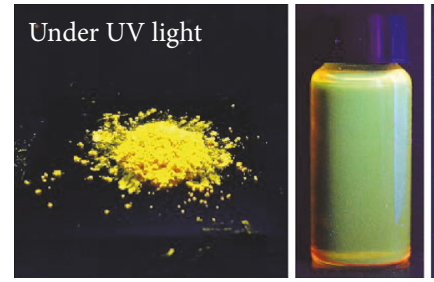

(d)

FiguRe 2

and 7189, respectively. The polymer-QDs nanocomposites (PTpC-QDs and PCzC-QDs) were obtained as follows: $0.5 \mathrm{~g}$ of each polymer (PTpC or PCzC) was dissolved with $20 \mathrm{~mL}$ of chloroform, and $1 \mathrm{~mL}$ of each QD (R, G, and B) solution was added to them. The mixture was stirred for $3 \mathrm{~h}$ at room temperature. The stirred solution was allowed to settle as a precipitate for about $5 \mathrm{~h}$. The mixture was filtered through Whatman filter paper, and the precipitate nanocomposite was collected for further analysis.

Measurements of the synthesized polymers and polymerQDs nanocomposites: The Fourier transform infrared (FTIR) spectra of the polymers were recorded in the range of 600 to $4000 \mathrm{~cm}^{-1}$ using a Bruker IFS 66V Fourier transform spectrometer. High resolution ${ }^{1} \mathrm{H}-\mathrm{NMR}$ spectra were recorded on a $500 \mathrm{~Hz}$ AVANCE III spectrometer in $\mathrm{CDCl}_{3}$ with tetramethylsilane as an internal standard. Thermogravimetric analysis (TGA) was performed on a Mettler TA 3000 thermal analyzer under a nitrogen atmosphere at a heating rate of $5^{\circ} \mathrm{C} \mathrm{min}^{-1}$ with a sample weight of $2-4 \mathrm{mg}$. Emission spectra were obtained from a Perkin-Elmer II fluorescence spectrophotometer.

Fabrication and measurement of the PLED devices: PLED devices were fabricated by using pure polymers (PTpC and PCzC), QDs (CdSeS@ZnS for red, CdZnSeS@ZnS for green, and CdZnS@ZnS for blue), and the polymer-QDs nanocomposites as an EML. $100 \mathrm{~nm}$ thick ITO electrode was deposited on Corning glass by sputtering for use as an anode.
The $40 \mathrm{~nm}$ thick poly(3,4-ethylenedioxythiophene)/poly(4styrenesulfonate) (PEDOT/PSS) as a HIL was coated on the ITO patterned substrates. The EMLs (PTpC, PCzC, QDs ( $\mathrm{G}$, and $\mathrm{B})$, PTpC-QDs (R, G, and $\mathrm{B})$, or PCzC-QDs (R, $\mathrm{G}$, and $\mathrm{B})$ ) with the thickness of $\sim 80 \mathrm{~nm}$ were spin-coated on HIL/ITO substrates. The $150 \mathrm{~nm}$ thick aluminum as a cathode electrode was then deposited onto the EML by using sputtering. The EL spectra and luminescence-current-voltage (LIV) characteristics of the fabricated PLED devices were recorded with a Konica-Minolta CS-1000 spectroradiometer coupled with a Keithley 2400 voltage and current source under ambient conditions.

\section{Results and Discussion}

A summary of the synthetic scheme of the target polymers, PTpC and PCzC, is presented in Figure 1(a). The synthesized polymers (PTpC and $\mathrm{PCzC}$ ) were confirmed by using FT-IR and ${ }^{1} \mathrm{H}-\mathrm{NMR}$ analysis. The FT-IR spectra of the polymers (PTpC and $\mathrm{PCzC}$ ) revealed the vibration frequencies of the materials (Figure 1(b)). The stretching vibration at $3083 \mathrm{~cm}^{-1}$ indicated the presence of aromatic $\mathrm{C}=\mathrm{C}$. The characteristic peak of the $\mathrm{C}-\mathrm{H}$ group appeared at $800-1200 \mathrm{~cm}^{-1}$. The characteristic carbonyl $(\mathrm{C}=\mathrm{O})$ band is assigned at $1707 \mathrm{~cm}^{-1}$ [12]. An intense sharp band at $1071 \mathrm{~cm}^{-1}$ was observed because of $\mathrm{C}-\mathrm{H}$ stretching vibration, and $-\mathrm{CH}_{2}$ ring stretching was also observed at $2857 \mathrm{~cm}^{-1}$. As shown in Figure 1(c), the ${ }^{1} \mathrm{H}-\mathrm{NMR}$ 


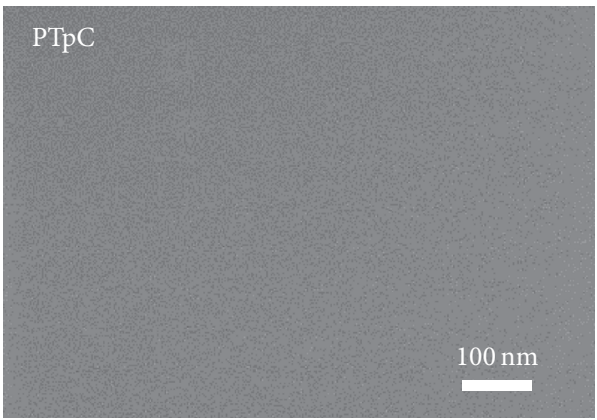

(a)
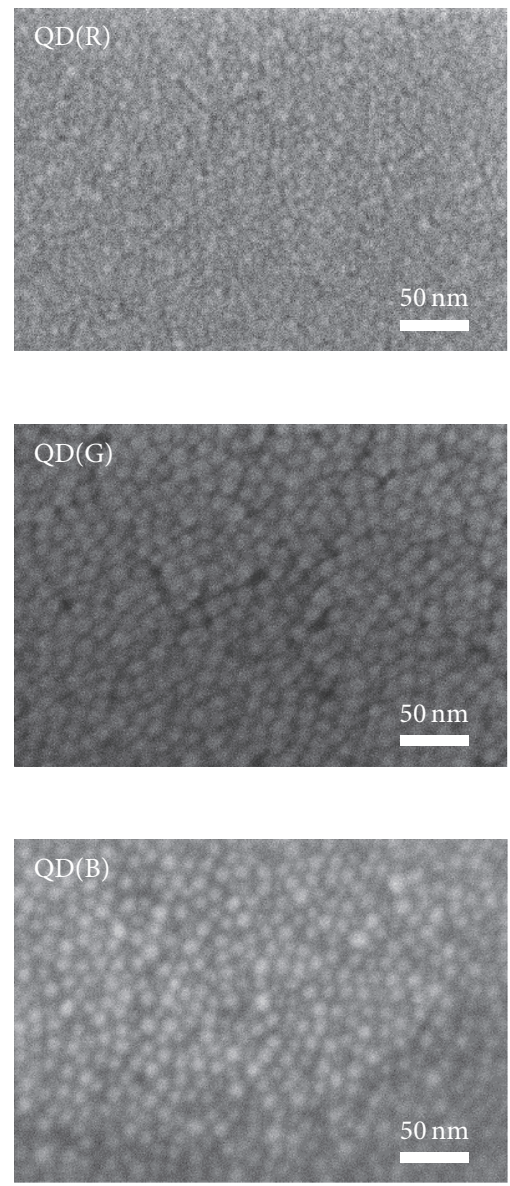

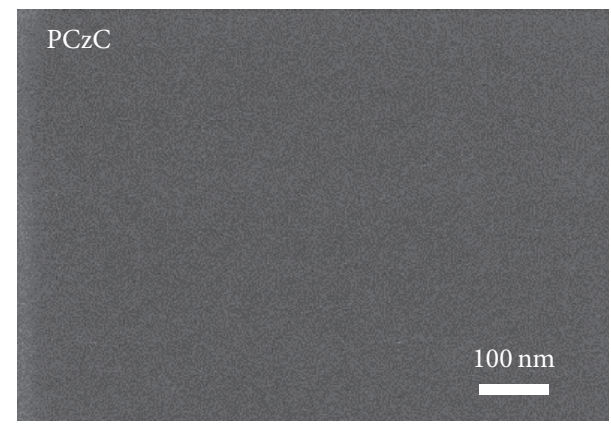

(b)
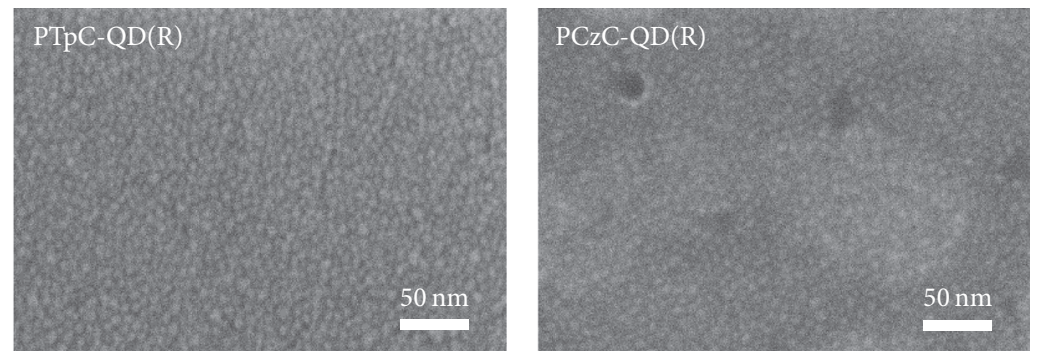

(c)
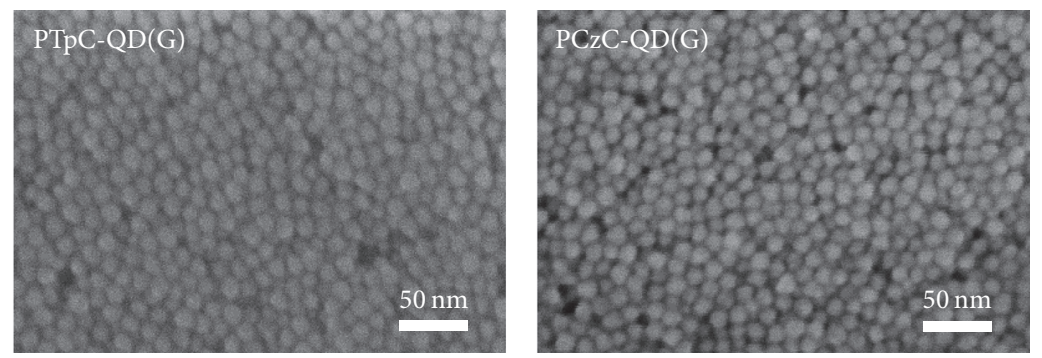

(d)
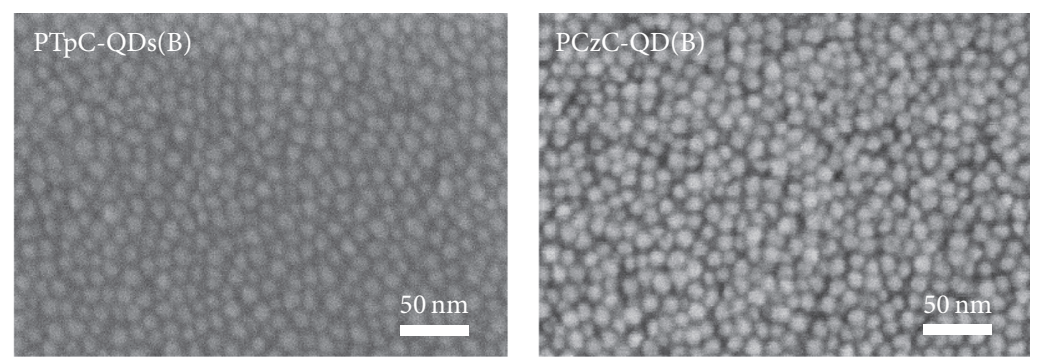

(e)

Figure 3

spectra of the polymeric compounds show multiplet peaks for each aliphatic $-\mathrm{CH}$ and $-\mathrm{CH}_{2}$ proton between 1.25 and $6.25 \mathrm{ppm}$. The multiplet peaks at 7-9 ppm were due to the presence of aromatic protons in PTpC and PCzC [10].

Thermal stability is a significant factor in PLED device, because a material with poor thermal stability causes rapid degradation of EML and leads to decomposition of materials at high temperature. The thermogravimetric analysis (TGA) was used to determine thermal stability of the synthesized polymers. Figure $1(\mathrm{~d})$ shows the TGA results of the synthesized polymers PTpC and PCzC. The initial weight loss $\left(T_{i}\right)$ occurred at $\sim 290$ and $295^{\circ} \mathrm{C}$ for $\mathrm{PTpC}$ and $\mathrm{PCzC}$, respectively, because of the first decomposition of the polymers. The second weight loss of PTpC and $\mathrm{PCzC}$ was obtained at $\sim 550$ and $560^{\circ} \mathrm{C}$, respectively. Both polymers, PTpC and $\mathrm{PCzC}$, were thermally stable up to 290 and $295^{\circ} \mathrm{C}$, respectively. These high $T_{i}$ values indicate that the thermal stability of polymers makes them suitable for the fabrication of PLED devices.

Figures 2(a) and 2(b) show the fluorescence spectra of $\mathrm{PTpC}$ and $\mathrm{PCzC}$ in power, solution, and thin film. The PTpC possessed a broad peak from $\sim 400$ to $650 \mathrm{~nm}$ in powder and the maximum emission peak at $540 \mathrm{~nm}$ in solution and 


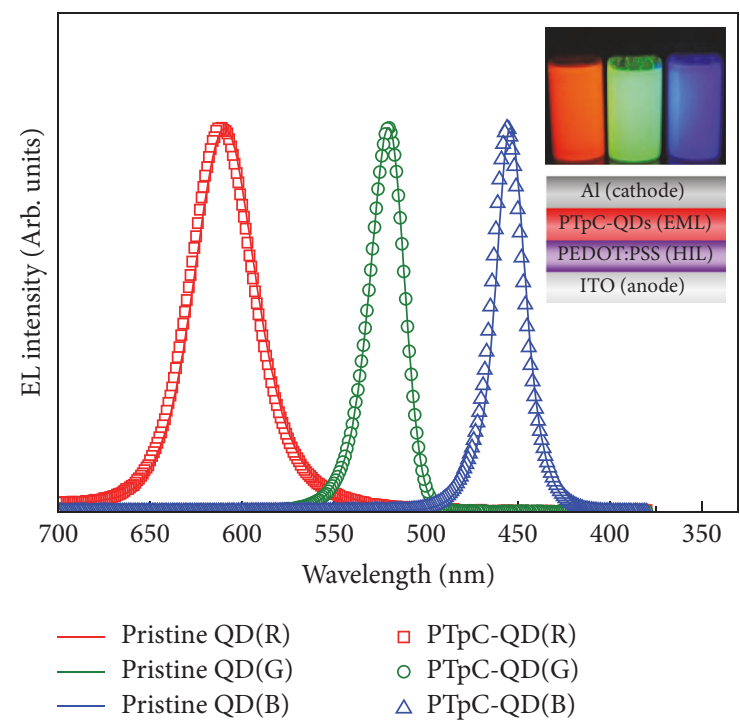

(a)
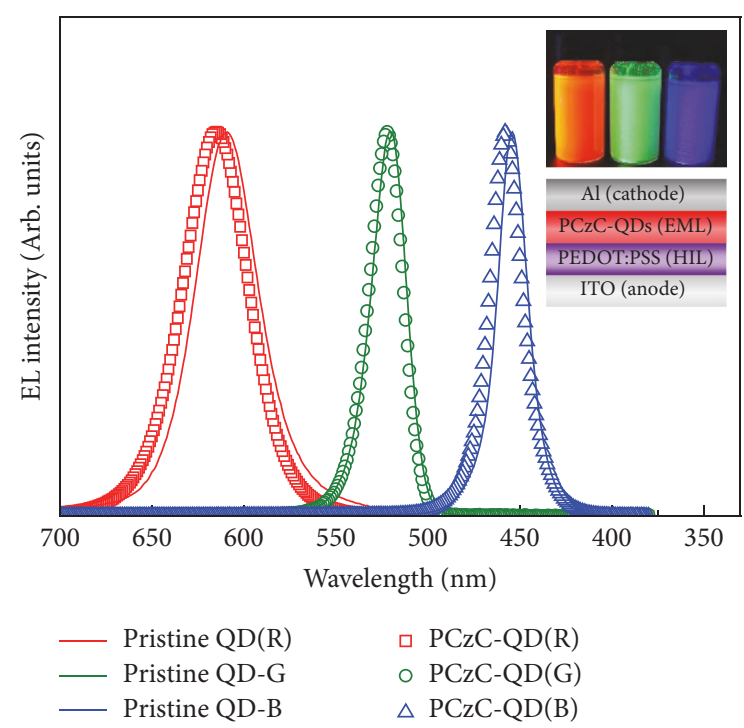

(b)
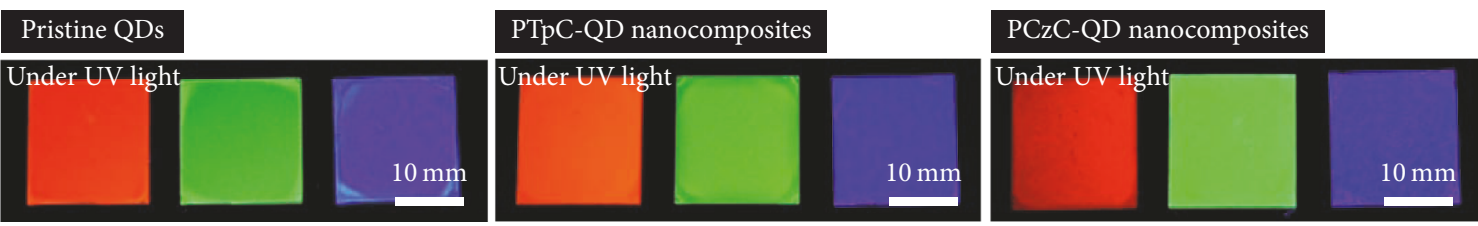

(c)

Figure 4

$560 \mathrm{~nm}$ in thin film. On the other hand, the PCzC exhibited a broad peak from 450 to $720 \mathrm{~nm}$ in powder and a maximum emission peak at $520 \mathrm{~nm}$ in solution and at $600 \mathrm{~nm}$ in thin film. The powders of PTpC and PCzC showed reddish yellow and yellow emission with a broad bandwidth. The emission peak of PTpC was red-shifted compared to that of $\mathrm{PCzC}$ because of the different substitution group of the polymers. Because PTpC has a more planar structure than PCzC, the molecules in PTpC are better aligned and possess higher molecular weight than in PCzC. As the molecular weight increases, the number of repeating units also increases. It leads to the $\pi$-conjugation extension of the polymer. The different maximum emission peaks of the PTpC and $\mathrm{PCzC}$ between thin film and solution were due to the well-aligned molecules and no interaction with solvent. The different bandwidth was due to the molecular arrangement of the polymers [16-18]. Since the molecular alignment in powder is much closer than that in solution and thin film, PTpC and $\mathrm{PCzC}$ in powder exhibit broad peaks. On the other hand, the $\mathrm{PTpC}$ and $\mathrm{PCzC}$ in solution show the narrow peak because the molecules were divided by the solvent interaction.

Figures 2(c) and 2(d) show the photo images of the PTpC and $\mathrm{PCzC}$ in powder, solution, and thin film states under UV light (365 nm) exposure. As shown in the figures, PTpC and $\mathrm{PCzC}$ in powder, solution, and thin film showed different colors under UV light exposure.

In order to secure an efficient charge transfer between the QDs and the polymer, it is important to control the dispersibility of the QDs in the polymer and the improvement of the interface between polymer and QDs. The dispersibility of the QDs in the polymer is directly related to the physisorption of polymers on the surface of QDs. The electroactive surfactants, such as the conjugated polymers, PTpC and $\mathrm{PCzC}$, could improve the transfer of charges between the QDs and the polymers. The polymer, which passivated the surface of QDs, could improve the interface between the polymer and QDs providing an efficient charge injection into the QDs. The interface between QD and polymer plays an important role in the determination of the luminescent properties of the PLED devices, because of the carrier transfer efficiency.

In order to observe the dispersibility of QDs in the polymer, the surface morphology of the two polymers (PTpC and PCzC), three QDs (CdSeS@ZnS for red, CdZnSeS@ZnS for green, and CdZnS@ZnS for blue), and six polymer-QDs nanocomposites were observed through the FE-SEM. The FE-SEM images of PTpC and PCzC in Figures 3(a) and 3(b) exhibited plain uniform morphology. In general, the polymer has the ability to form a smooth and plain morphology, because of its repeating units and high molecular weight. The triphenyl and carbazole group induced aggregation of the polymer molecules and $\pi-\pi$ stacking interaction between the molecules, resulting in a uniform surface morphology. Figures 3(c) and 3(e) illustrate the FE-SEM morphology of the three QDs before and after combining with PTpC or PCzC. As depicted in the figures, the QDs were binding well with the polymers, showing uniform spherical structure. This result 


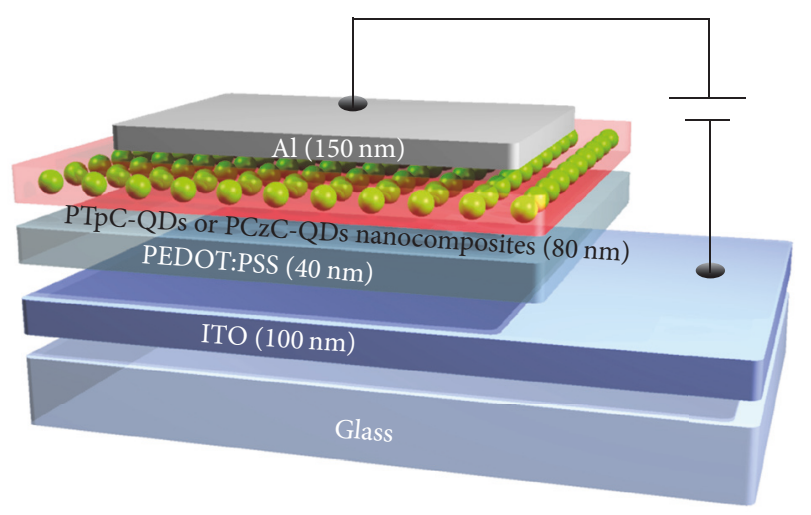

(a)

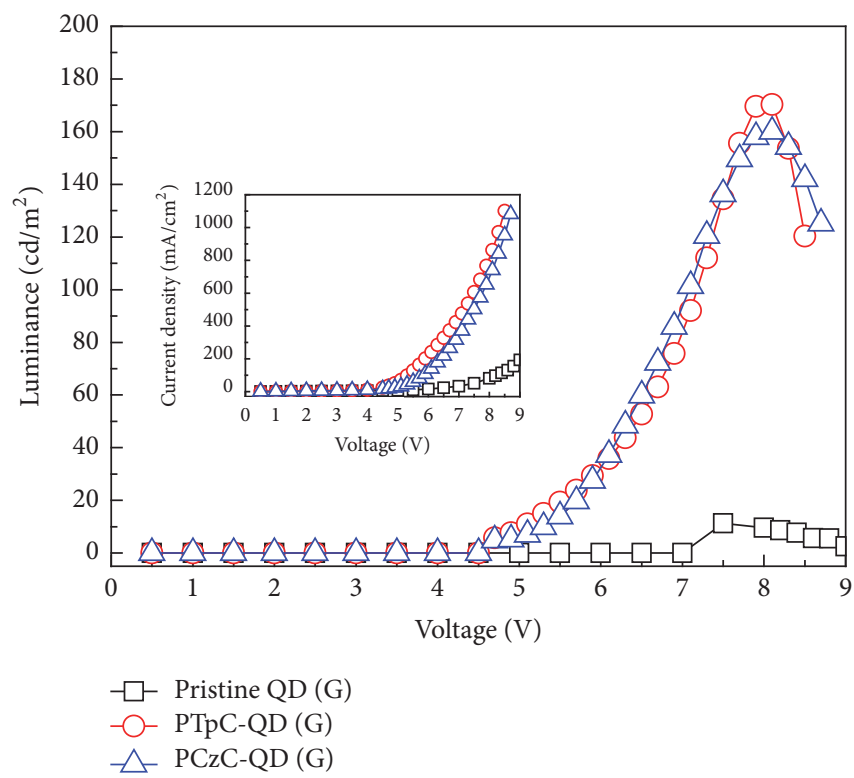

(c)

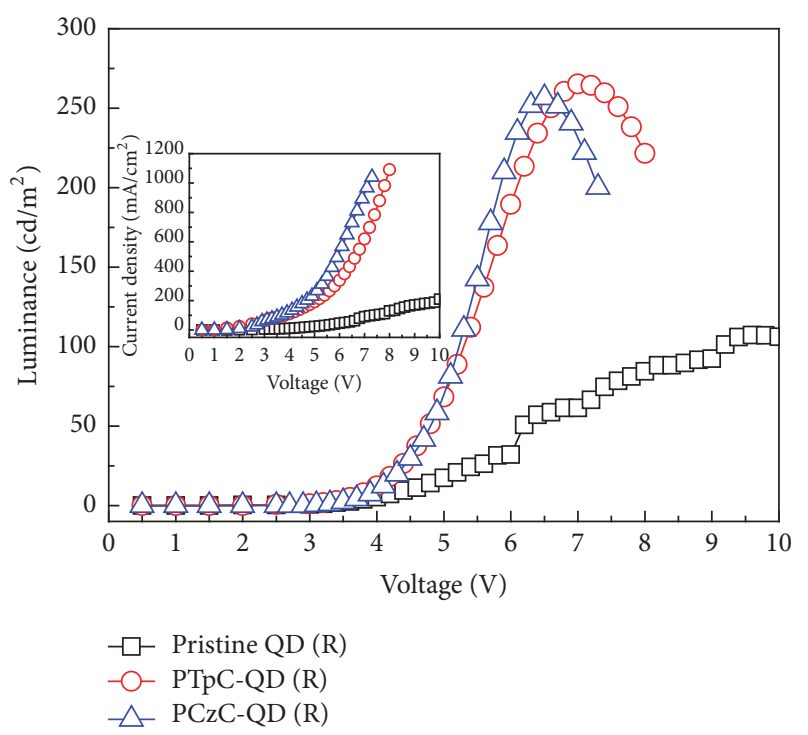

(b)

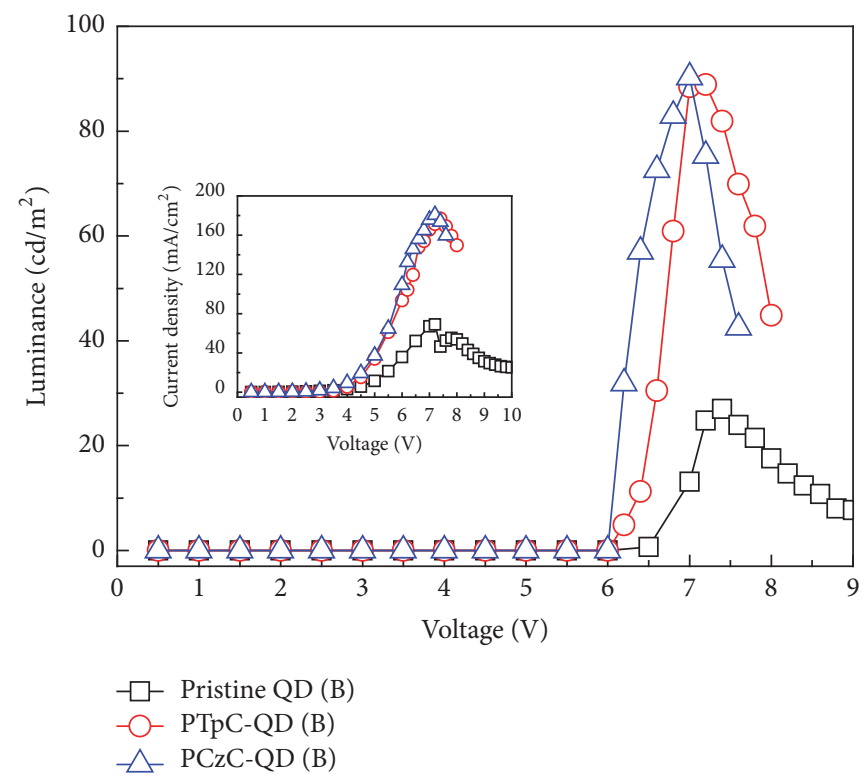

(d)

Figure 5

indicates that polymer-QDs nanocomposites could provide uniform dispersion of the QDs phase throughout the host polymer matrix on the microscopic level.

Figure 4 shows the normalized electroluminescence spectra of the pristine QDs and polymer-QDs nanocomposites in thin films. The pristine QDs (R, G, and B) exhibited emission peaks at 615,525 , and $445 \mathrm{~nm}$, respectively. The EL spectra of PTpC-QDs (R, G, and B) nanocomposites exhibited three peaks, 617,529 , and $450 \mathrm{~nm}$, while the PCzC-QDs (R, G, and B) nanocomposites possess peaks at 620,528 , and $452 \mathrm{~nm}$, respectively. The relative peaks of the PCzC-QDs (R, G, and $\mathrm{B}$ ) nanocomposite devices were $\sim 2-5 \mathrm{~nm}$ red-shifted to PTpC-QDs (R, G, and B) nanocomposite devices, indicating that the recombination zone of electrons and holes in the carbazole is higher than that of the triphenylamine based nanocomposite. Figure 4(c) presents different blue, green, and red emission images of the polymer-QDs nanocomposites on the plastic substrates under UV $(365 \mathrm{~nm})$ illumination. The strong blue, green, and red emissions were obtained for both the pristine QDs and polymer-QDs nanocomposites. The emission behaviors of the polymer-QDs nanocomposites are based on the charge transfer of the molecule, which occurs between the $\mathrm{C}=\mathrm{O}$ parts of the chalcone group. The conjugation part of the polymer acts as an electron transfer and linking group between the triphenyl amine and carbonyl group $(\mathrm{C}=\mathrm{O})$ of the polymer. 
Figure 5(a) shows the schematic of the device structure of ITO (100 nm)/PEDOT:PSS (40 nm)/EML (80 nm)/Al $(150 \mathrm{~nm})$. Figures $5(\mathrm{~b})-5(\mathrm{~d})$ show the LIV characteristics of the three types of devices by using the pristine QDs $(R, G$, and B), PTpC-QDs (R, G, and B) nanocomposites, and PCzCQDs $(R, G$, and $B)$ nanocomposites as an EML. The turnon voltages of the devices of the pristine $Q D s(R, G$, and $B)$, PTpC-QDs ( $R, G$, and $B$ ) nanocomposites, and PCzC-QDs $(\mathrm{R}, \mathrm{G}$, and $\mathrm{B})$ nanocomposites were $4.6,7.5,7.0,4,5.1,6.4$, 4.1, 5.3, and 6.2 V, respectively. The PTpC-QDs or PCzC-QDs nanocomposites showed a low turn-on voltage compared to those of the pristine polymer and the pristine QDs, owing to the high charge transporting ability of the polymers. The triphenylene and carbazole groups are usually considered as electron donors, and they have an excellent hole transporting property as well. The maximum luminance values of the devices with the pristine QDs ( $R, G$, and $B), P T p C-Q D s(R$, $\mathrm{G}$, and $\mathrm{B}$ ) nanocomposites, and PCzC-QDs (R, G, and $\mathrm{B}$ ) nanocomposites were observed as $107,11,27,265,170,89,256$, 160 , and $90 \mathrm{~cd} / \mathrm{m}^{2}$, respectively. The fabrication part involves the bilayer efficiency analysis of the raw QDs, polymers, and polymer nanocomposites (PTpC-QDs and PCzC-QDs). The devices with the pristine QDs as an EML showed very low luminance values due to the lack of the other layers (HTL, ETL, and EIL), which made it difficult to apply the hole injection to EML and resulted in an unbalanced number of electrons and holes in the EML. On the other hand, PTpC-QDs and PCzC-QDs nanocomposites showed higher luminance properties due to the charge transfer between the QDs and the polymer. The insets in Figure 5 show current density of the pristine QDs (R, G, and B), PTpC-QDs (R, $\mathrm{G}$, and $\mathrm{B}$ ) nanocomposites, and $\mathrm{PCzC}-\mathrm{QDs}(\mathrm{R}, \mathrm{G}$, and $\mathrm{B})$ nanocomposites.

Since the physicochemical properties of the PTpC-QDs and $\mathrm{PCzC}-\mathrm{QDs}$ nanocomposites differed from those in the parent materials, PTpC and PCzC, the charge mobility and the emission properties of the nanocomposites were different from those in the pristine polymer and the pristine QDs. The presence of QDs in the polymer enhances the photoinduced charge generation efficiency, while the polymer can be responsible for the charge transport to the electrodes. The energy levels of the polymeric host and the QDs can be tuned by a different polymeric backbone and by mixing the QDs with the polymer. These modifications increase the charge transport and luminance of the PELD devices. As a result, a polymer-QD nanocomposite device could provide enhanced hole/electron injection and luminance efficiency compared to polymer-only and QDs-only devices.

\section{Conclusion}

In summary, we reported on two polymer (PTpC and PCzC)-QDs nanocomposites for PLEDs. The two polymers were used as grafting agents on core-shell QD nanoparticles. Electron transfer processes between the QDs and the surrounding polymer matrix are essential in a range of optoelectronic devices including PLEDs. Functionalization of the QD surface with electroactive polymers was therefore explored with the aim of facilitating the charge transfer across the interface between polymer and QDs. These hybrid polymer-QDs nanocomposites possess versatile properties, providing luminescence enhancement based on the increase of conductivity and the uniform formation of thin film. The fabricated PLED devices with polymer-QDs nanocomposites as an EML showed better luminescent characteristics compared to those of PLED devices with the pristine polymer or the pristine QDs as EML. The charge transfer between the QDs and the polymer played a key role for the increase of luminescence and efficiency of the PLED devices with polymer-QDs nanocomposites. The proposed polymer-QDs nanocomposite materials could be significant candidates for application in PLEDs.

\section{Conflicts of Interest}

The authors declare that they have no conflicts of interest.

\section{Acknowledgments}

This work was supported by the National Research Foundation of Korea (NRF) grant funded by the Korean Government (MSIP) (2014R1A2A1A11049450, 2015R1A2A1A15053268, and 2016M3A7B4910458).

\section{References}

[1] R. Hofmockel, U. Zschieschang, U. Kraft et al., "High-mobility organic thin-film transistors based on a small-molecule semiconductor deposited in vacuum and by solution shearing," Organic Electronics, vol. 14, no. 12, pp. 3213-3221, 2013.

[2] S. Fusco, C. Maglione, A. Velardo et al., "N-Rich Fused Heterocyclic Systems: Synthesis, Structure, Optical and Electrochemical Characterization," European Journal of Organic Chemistry, vol. 2016, no. 9, pp. 1772-1780, 2016.

[3] D. Di, L. Yang, J. M. Richter et al., "Efficient Triplet Exciton Fusion in Molecularly Doped Polymer Light-Emitting Diodes," Advanced Materials, vol. 29, no. 13, Article ID 1605987, 2017.

[4] A. Menon, H. Dong, Z. I. Niazimbetova, L. J. Rothberg, and M. E. Galvin, "Polydispersity effects on conjugated polymer lightemitting diodes," Chemistry of Materials, vol. 14, no. 9, pp. 3668$3675,2002$.

[5] J. Huang, G. Li, E. Wu, Q. Xu, and Y. Yang, "Achieving highefficiency polymer white-light-emitting devices," Advanced Materials, vol. 18, no. 1, pp. 114-117, 2006.

[6] L. Chen, B. Zhang, Y. Cheng et al., "Pure and saturated red electroluminescent polyfluorenes with dopant/host system and PLED efficiency/color purity trade-offs," Advanced Functional Materials, vol. 20, no. 18, pp. 3143-3153, 2010.

[7] D. Acierno, E. Amendola, S. Bellone et al., "Synthesis and characterization of a new class of nematic photoluminescent oxadiazole-containing polyethers," Macromolecules, vol. 36, no. 17, pp. 6410-6415, 2003.

[8] C. S. Ponseca, H. Němec, N. Vukmirović et al., "Electron and hole contributions to the terahertz photoconductivity of a conjugated polymer:Fullerene blend identified," The Journal of Physical Chemistry Letters, vol. 3, no. 17, pp. 2442-2446, 2012.

[9] S. Fusco, R. Centore, P. Riccio et al., "NLO-active polymers containing triazolo-thiadiazole segments," Polymer Journal, vol. 49, no. 1, pp. 186-191, 2008. 
[10] S. Cho, J. Kwag, S. Jeong, Y. Baek, and S. Kim, "Highly fluorescent and stable quantum dot-polymer-layered double hydroxide composites," Chemistry of Materials, vol. 25, no. 7, pp. 1071-1077, 2013.

[11] A. P. Alivisatos, "Semiconductor clusters, nanocrystals, and quantum dots," Science, vol. 271, no. 5251, pp. 933-937, 1996.

[12] J. Shi, S. Gider, K. Babcock, and D. D. Awschalom, "Magnetic clusters in molecular beams, metals, and semiconductors," Science, vol. 271, no. 5251, pp. 937-941, 1996.

[13] R. Kisslinger, W. Hua, and K. Shankar, "Bulk heterojunction solar cells based on blends of conjugated polymers with ii-vi and iv-vi inorganic semiconductor quantum dots," Polymer, vol. 9, no. 2, pp. 1-29, 2017.

[14] M. Mao, C. Zhou, H. Shen, H. Wang, S. Wang, and L. S. Li, "Bright, transparent, and light-emitting films using fluorescent QDs-polystyrene composite microspheres," Materials Letters, vol. 111, pp. 97-100, 2013.

[15] V. Sankaran, C. C. Cummins, R. R. Schrock, R. E. Cohen, and R. J. Silbey, "Small PbS clusters prepared via ROMP block copolymer technology," Journal of the American Chemical Society, vol. 112, no. 19, pp. 6858-6859, 1990.

[16] W. Wang, F. Zhang, L. Li, M. Gao, and B. Hu, "Improved Performance of Photomultiplication Polymer Photodetectors by Adjustment of P3HT Molecular Arrangement," ACS Applied Materials \& Interfaces, vol. 7, no. 40, pp. 22660-22668, 2015.

[17] Y. Huang, W. Zheng, Y. Qiu, and P. Hu, "Effects of organic molecules with different structures and absorption bandwidth on modulating photoresponse of MoS2 photodetector," ACS Applied Materials \& Interfaces, vol. 8, no. 35, pp. 23362-23370, 2016.

[18] C. Hellmann, N. D. Treat, A. D. Scaccabarozzi et al., "Solution processing of polymer semiconductor:Insulator blends - Tailored optical properties through liquid-liquid phase separation control," Journal of Polymer Science Part B: Polymer Physics, vol. 53, no. 4, pp. 304-310, 2015. 

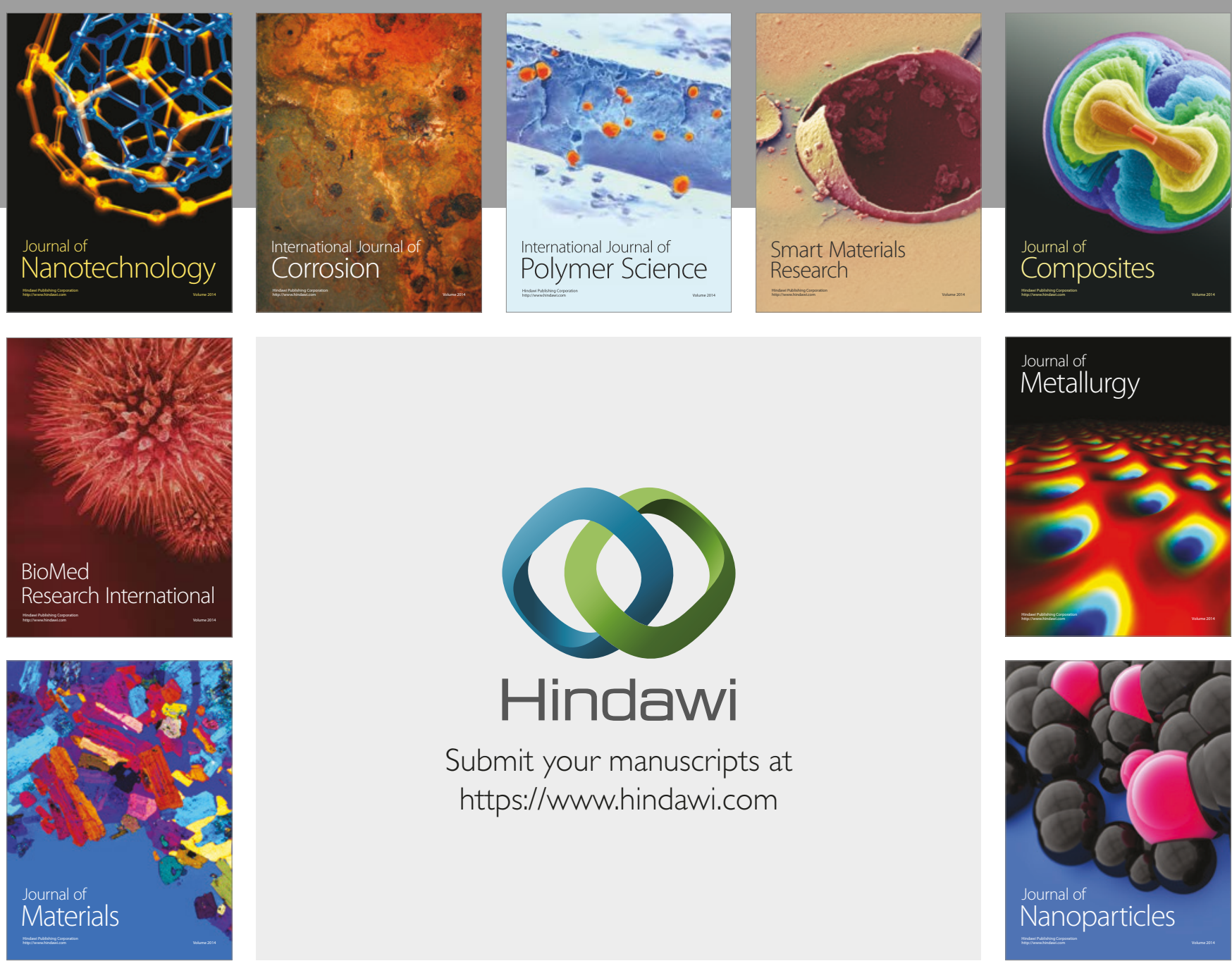

\section{Hindawi}

Submit your manuscripts at

https://www.hindawi.com
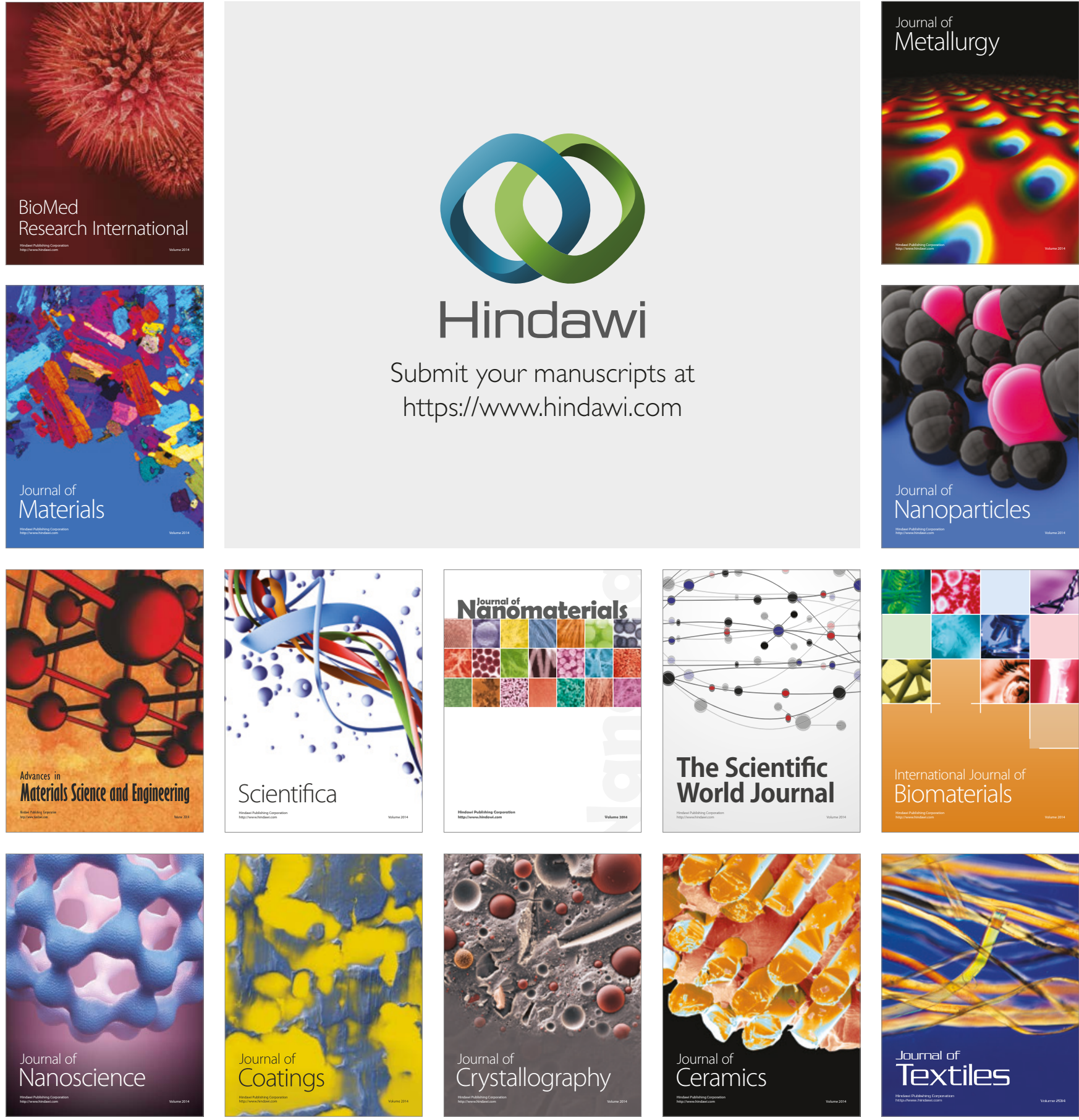

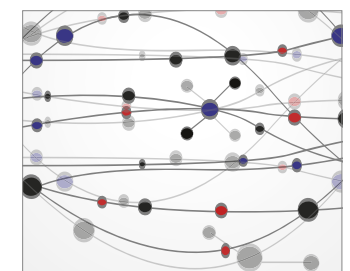

The Scientific World Journal
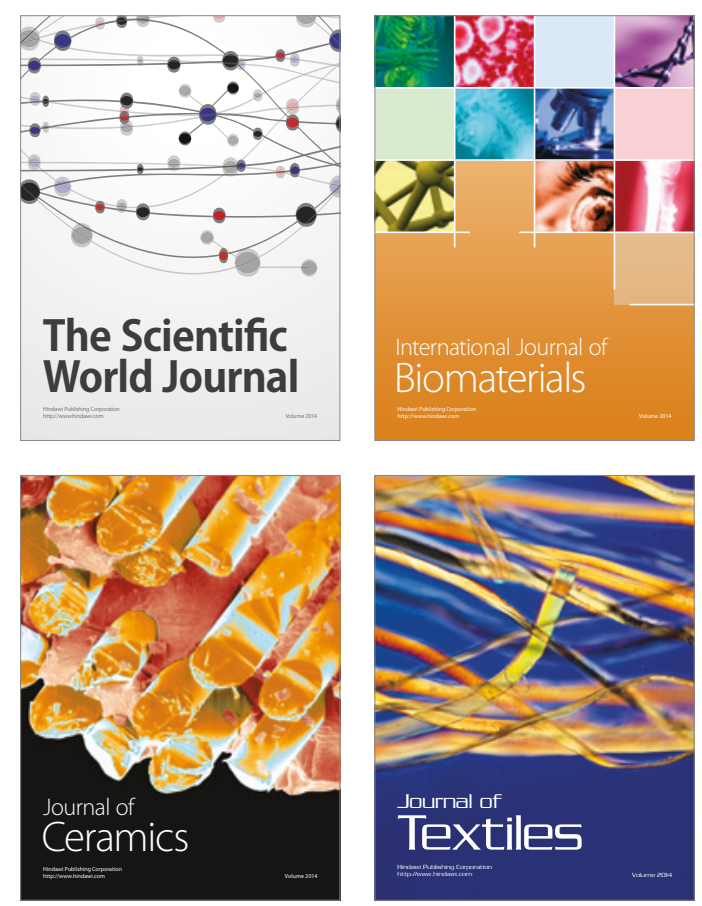